\title{
Tobacco and Oral Diseases
}

\author{
Update on the Evidence, with Recommendations
}

\author{
Jesper Reibel \\ Department of Oral Medicine, Clinical Oral Physiology, Oral Pathology \& Medicine, School of Dentistry, \\ University of Copenhagen, Copenhagen, Denmark
}

\author{
Key Words \\ Oral health $\cdot$ Tobacco $\cdot$ Smoking
}

\begin{abstract}
It is well known that smoking contributes to the development of lung cancer and cardiovascular disease, and there is weighty evidence that it has a considerable influence on oral health. Smoking has many negative effects on the mouth, including staining of teeth and dental restorations, reduction of the ability to smell and taste, and the development of oral diseases such as smoker's palate, smoker's melanosis, coated tongue, and, possibly, oral candidosis and dental caries, periodontal disease, implant failure, oral precancer and cancer. From a qualitative point of view the latter is obviously the most serious tobacco-related effect in the mouth. Quantitatively, however, importance has been attached to periodontitis, which affects a large proportion of the population, and during recent years more attention has been given to implant survival rates. Dentists have an important role to play in preventing the harmful effects of smoking in the mouth, and consequently smoking counselling should be as much a part of the dentist's job as plaque control and dietary advice.
\end{abstract}

Copyright @ 2003 S. Karger AG, Basel

\section{Introduction}

The role of smoking in the development of lung cancer and cardiovascular disease is well known. Since the initial suspicion of the relation between smoking and lung cancer in the 1950s [1], the famous study of British doctors, among many others, established a causal relationship between smoking and death from major diseases, including cancer of the lung and other types of cancer, respiratory diseases such as obstructive pulmonary disease, vascular diseases, and peptic ulcers [2, 3]. As part of the healthcare system dentists have an obvious interest in these diseases, but it could be argued that other members of the health system have more important roles to play as far as these and many other smoking-related diseases are concerned. However, since there is weighty evidence that smoking has a considerable influence on oral health, it is not unreasonable that dentists should play an important role in preventing the harmful effects of smoking on human tissues in general and oral tissues in particular.

The oral effects of smoking range from harmless stains of teeth and dental restorations to serious diseases such as oral cancer (table 1). From a qualitative point of view the latter, obviously, is of utmost importance, since the fiveyear relative survival rate for intraoral cancer is about 50\% [4]. Quantitatively, however, importance has been attached to other diseases or issues related to smoking such as periodontitis, which affects a large proportion of

Jesper Reibel

School of Dentistry

20, Norre Allee

DK-2200 Copenhagen N (Denmark)

Tel. +45 35326720, Fax +45 35326722, E-Mail jesper.reibel@odont.ku.dk 
Table 1. Effects of smoking on the mouth

Discolorations of teeth and restorations

Coated/hairy tongue

Reduced ability to taste and smell

Smokers' melanosis

Smokers' palate

Dental caries

Oral candidosis

Increased failure rates for dental implants

Periodontal disease

Smokers' white patch/leukoplakia

Oral cancer

Table 2. Oral cancer: age-standardized (world population) incidence rates per 100,000 [9]

\begin{tabular}{lrl}
\hline Population & Men & Women \\
\hline Denmark & 6.5 & 2.1 \\
UK: England and Wales & 3.2 & 1.3 \\
France: Bas-Rhin & 21.0 & 2.1 \\
US: Iowa & 8.2 & 2.6 \\
China: Shanghai & 1.8 & 1.3 \\
Hong Kong & 4.1 & 2.0 \\
Japan: Osaka & 3.0 & 1.3 \\
Thailand: Chang Mai & 4.7 & 2.5 \\
India: Trivandum & 8.2 & 2.5 \\
\hline
\end{tabular}

the population, or implant survival, which has come into focus more and more during recent years.

There are several general reviews and informational booklets for dentists on the effects of smoking in the mouth $[5,6]$. Within the European Union (EU) the Working Group on Tobacco and Oral Health distributed informational material to dentists in EU countries and published a comprehensive review from a consensus meeting organized by the Working Group [7]. Part of this consensus paper has been cited at www.whocollab.od.mah.se/ expl/tobacco.html.

The aim of this article is to provide a concise, didactic update on the effects of smoking on oral health, with an emphasis on recent evidence and achievements. When possible, reference is given to detailed and comprehensive reviews of available literature in the field. Also provided are practical and realistic guidelines for dentists to help their patients in their efforts to quit smoking.

\section{Oral Cancer}

The majority of oral cancers, constituting $2-3 \%$ of all cancers worldwide [8], are squamous cell carcinomas developing from the mucosal surface epithelium (fig. 1) [4]. Oral cancer affects mostly middle-aged or elderly people and is more common in men than in women [8]. The incidence varies worldwide (table 2) [9]. In this report, oral cancer is used synonymously with squamous cell carcinoma originating from the mucosal surface epithelium.

Numerous studies in various populations have shown that smokers have a substantially higher risk of oral cancer than nonsmokers [10-16]. The studies are primarily concerned with the use of cigarettes, but pipe and cigars seem to carry an equal or even higher risk $[13,16]$. There is a clear dose-response relationship, with risk decreasing after smoking cessation. In some studies it was shown that 10 years after quitting, former smokers have the same risk of oral cancer as people who never smoked, whereas other studies show that the risk decreases dramatically but remains at a level somewhat higher than that found in people who never smoked $[12,17]$. Ethnic differences in the incidence and mortality of oral cancer exist, but the information available is scarce $[18,19]$.

The relationship between the use of smokeless tobacco and oral cancer has been discussed at length. The apparent discrepancies between different researchers probably derive from the fact that there are great differences in habits and products around the world, which makes a general statement on this subject impossible. Snufff-habits as they appear in Scandinavia carry none or very low risks of oral cancer [20,21], but the use of other types of smokeless tobacco in other parts of the world seems to pose a substantial cancer risk [22].

Although the underlying mechanisms are not known in detail, it is plausible that smoking could lead to cancer since carcinogens in tobacco smoke can induce changes in DNA. In recent years much attention has been given to smoking-related mutations in a tumor suppressor gene coding for the protein $\mathrm{p} 53$. This protein is important in regulating cell proliferation and has a role in the repair of DNA damage [23]. Mutations in the gene may lead to an accumulation of DNA damage in the cells, which may play an important role in the development of cancer.

Many studies on the relationship between smoking and oral cancer have been appropriately controlled for various confounders such as diet (low intake of fresh fruit and vegetables increases the risk of developing oral cancer [24, 25]), social status, and, not the least important, alcohol abuse. Smoking and excessive alcohol intake synergisti- 
cally increase the risk of developing oral cancer $[10,12$, 14]; it has been estimated that between 75 and $90 \%$ of all cases are explained by the combined effect of smoking and alcohol use. This could be because alcohol dissolves certain carcinogenic compounds in tobacco smoke and/or alcohol increases the permeability of the oral epithelium [26]. In Greece, where the incidence of oral cancer in general is low, a study showed a similar synergistic effect between tobacco and alcohol [27], and in a study on 300 patients at an addiction unit in Hungary, 8 oral carcinomas were diagnosed (2.7\%, mean age 39 years) [28]. All of the 300 patients had a daily smoking and alcohol habit; about half of them smoked more than 20 cigarettes a day and consumed the equivalent of 2-3 liters of wine daily. Thus, screening of risk groups, defined primarily by tobacco and alcohol habits, seems well founded.

There is overwhelming and consistent evidence that smoking causes oral cancer. A recent study, however, showed that only one third of patients who had undergone treatment for oral cancer [29]! Thus, the public needs to be informed of the risks, in particular during their visits to the dental office.

\section{Oral Precancer}

Oral leukoplakia, the most common premalignant lesion in the mouth, is far more common in smokers than in non-smokers (fig. 2) [30, 31]. A recent study suggests that leukoplakias in the floor of the mouth are associated with smoking habits, whereas leukoplakias at the lateral borders of the tongue are more common among nonsmokers [32]. Smokeless tobacco induces wrinkled changes in the oral mucosa at the site where the quid is placed [20, 33$36]$, but at least some of these changes seem to be reversible [36, 37].

Bearing in mind the role of smoking in the development of oral cancer, it is not easy to understand why leukoplakias associated with a smoking habit seem to have a better prognosis in terms of future transformation to cancer than those in non-smokers [38, 39]. In populationbased studies from India it has been shown that cessation of tobacco use substantially decreases the incidence of oral leukoplakias [40], and since it has been shown recently that smoking is positively correlated to the presence of epithelial dysplasia in oral precancerous lesions [41], it is fair to conclude that it is an important and necessary task for the dentist to inform patients of the relationship between smoking and oral leukoplakias.
An explanation for the finding that leukoplakias associated with a smoking habit have a better prognosis than those not associated with a smoking habit could be that a proportion of smoking-related leukoplakias may not have reached the point of no return. Thus, after smoking cessation a substantial number of smoking-related leukoplakias will disappear [42]. This subgroup of smoking-related leukoplakias may have a low malignant potential. Is it possible, then, to predict if a given white lesion will disappear upon smoking cessation? There is at least one characteristic clinical finding that tells us that the lesion is tobacco-induced: fine white striae that imitate a fingerprint pattern in the mucosa [43]. These lesions are referred to as fingerprint lesions or a pumice stone type of lesion (fig. 3). They will invariably disappear upon tobacco cessation (fig. 4) and are generally regarded as non-premalignant. If a comparison was made between leukoplakias not associated with a smoking habit and leukoplakias associated with a smoking habit but failing to disappear upon smoking cessation, the malignant potential would presumably be the same. The latter group of leukoplakias would possibly include smoking-induced leukoplakias as well as leukoplakias that developed independently of the patient's smoking habit. Thus, without knowing the fate of a given leukoplakia upon smoking cessation the wording 'smoking-induced' should be avoided in favor of the wording 'smoking-associated'.

\section{Periodontal Disease}

During the last 20 years numerous cross-sectional and longitudinal studies have demonstrated a clear relationship between smoking and periodontal disease [for reviews, see 44, 45]. Periodontitis is more prevalent and more severe in smokers, characterized by deeper periodontal pockets, greater attachment loss and more furcation defects [46-52]. In many studies smoking was suggested to be an independent risk factor for periodontal disease after controlling other factors: oral hygiene, plaque, calculus, and socioeconomics. The relative risk of periodontal disease among smokers has been reported to be between 2.5 and 6 compared to nonsmokers [47, 49]. Initially, it was thought that a higher amount of plaque in smokers explained such findings, but the rate of plaque accumulation does not seem to be higher in smokers than in nonsmokers $[53,54]$.

Recent studies, a few of which are population-based, support earlier findings on periodontal disease in smokers [55-61] and show that cigar and pipe smoking have simi- 

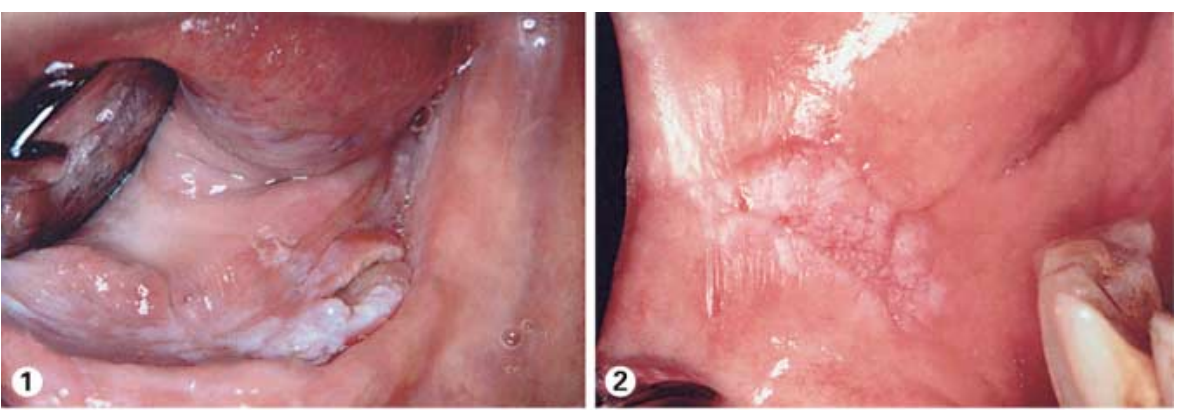

Fig. 1. Squamous cell carcinoma in the floor of the mouth in a heavy smoker.

Fig. 2. Leukoplakia characterized by whitish changes, erythematous areas, and nodules in the right buccal commissure in a heavy smoker. Biopsy revealed slight epithelial dysplasia and candidosis. Some would classify this lesion as a chronic hyperplastic candidosis.

Fig. 3. White changes in right buccal commissure in a heavy smoker. Note fingerprint-like pattern or pumice stone appearance.

Fig. 4. Same lesion as in figure 3 after 3 months' of tobacco abstinence.

Fig. 5. Smokers' palate in pipe smoker.

Fig. 6. Smokers' melanosis in the floor of the mouth in a heavy smoker.
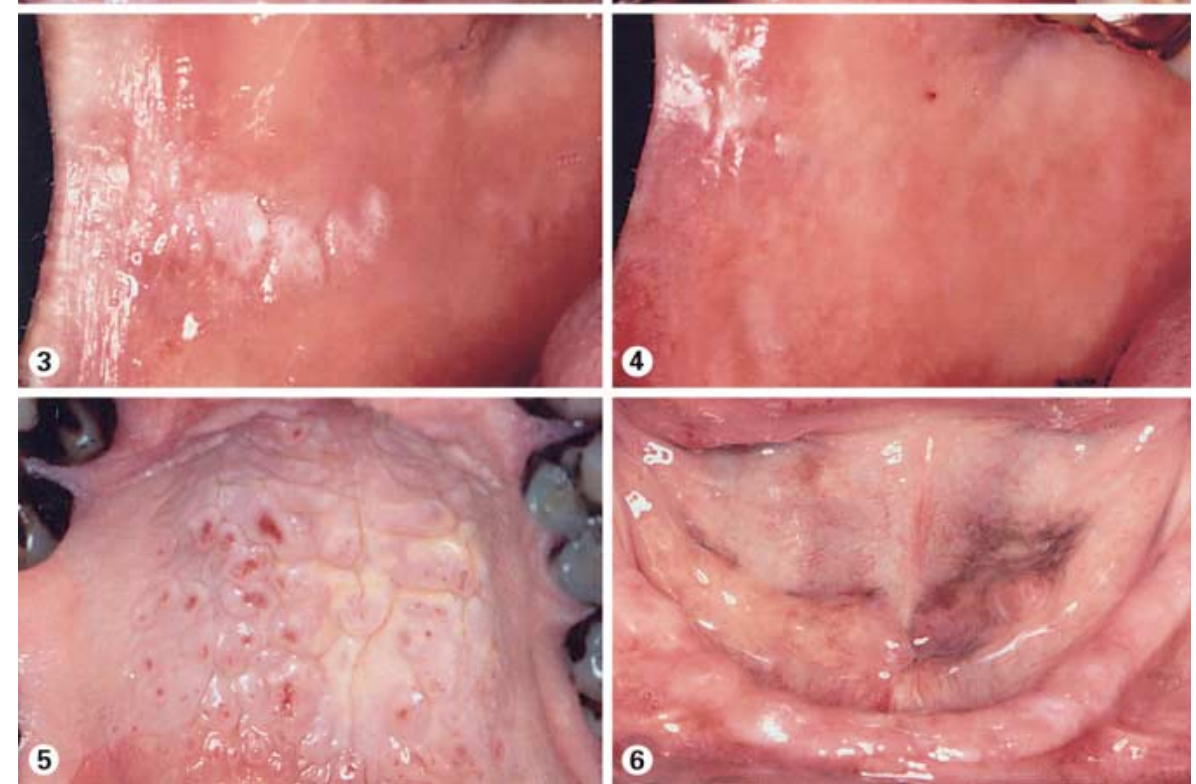

lar effects as cigarettes [55]. A dose-dependent response has been suggested $[48,56,62]$, strengthening the evidence that smoking is a risk factor for periodontal disease. Furthermore, the disease is more severe in current smokers as compared to former smokers [56, 59, 63, 64]. It should be emphasized, however, that studies comparing periodontal disease in current and former smokers were not randomised. The patients who succeed in stopping their smoking habit might be a subgroup of smokers who have an otherwise healthier way of life than those who continue to smoke. But randomising smoking cessation in a scientific context might not be feasible and would, furthermore, pose ethical problems.

The effect of smoking on adult patients with manifest periodontitis could be blurred by general health problems and by the progressive process of periodontal disease itself. A recent study on young healthy people without or with minimal periodontitis, however, reveals a clear negative effect of smoking on the periodontal tissues [65].

The mechanisms underlying the negative effects of smoking on periodontal tissues are largely unknown.
Studies have shown more periopathogens in smokers than in nonsmokers, but other studies have not supported this finding. Divergent results are likewise seen in recent studies [66-68]. Most of these studies were conducted on patients with severe periodontitis, but a recent study on young adults with healthy periodontium showed that typical periopathogens are more frequent in smokers than in nonsmokers after controlling variations in oral hygiene, suggesting that smoking is involved in the early development of the disease. A recent study suggested that the effect of smoking on periodontal disease was a reduction in the regression of the disease rather than an effect on the progression of disease [69].

Since divergent results on the composition of the subgingival microflora have been reported, an explanation of the effect of smoking on periodontal tissues has been sought in smoking-induced alterations in the host response. Based on recent reviews [44, 70], it seems fair to conclude that plausible biological explanations exist. Recent studies support earlier findings of impaired humoral, cellular and innate immune reactions and effects via the 
cytokine and adhesion molecule systems [71-75]. A clinically suppressed hemorrhagic responsiveness of the periodontium has been demonstrated in smokers [76]. This may make it more difficult to detect early stages of diseases in smokers and might interfere with diagnostic tests on disease severity and activity.

Treatment failures seem to predominate among smokers, although the effect of smoking on treatment success is variable [for review, see 44]. The results of recent studies are in line with these findings $[58,77]$. Former smokers seem to respond to periodontal therapy in a manner similar to nonsmokers, but as mentioned above smokers who decide to stop smoking and succeed in their efforts may differ in other risk characteristics from smokers who do not quit their habit.

The use of smokeless tobacco has been associated with local gingival recession at the site of placement, but there is no evidence that it is associated with generalized or severe periodontal disease [78].

In concluding this section it can be stated that there is no doubt that smoking negatively influences periodontal health, although to what degree may be difficult to assess because most studies were done on selected patient groups and the results are difficult to apply directly to the general population. Further evidence is needed to determine the effect of smoking cessation on disease progression and treatment and the basic causal connection between smoking and periodontal disease still needs to be elucidated. A recent study assessing the evidence for a causal association between smoking and adult periodontitis suggests that such an association exists, but randomized controlled human prospective studies or community intervention studies are needed [79]. There is substantial evidence that intervention in the smoking habits of the patients should form an integral part of treatment plans and general preventive measures in the dental setting.

\section{Implant Survival}

Several studies have indicated a negative effect of smoking on the survival of dental implants [for review, see 80], and recent studies support this finding [81-84]. In some studies, however, patient characteristics are not reported in detail, confounding factors do not always seem optimally controlled, and multivariate analyses are rarely included. Implant failures believed to be attributable to smoking seem to be more common in the maxilla than in the mandible. Contrary to the general previous belief, it has been recently suggested that the increase in the number of implant failures in smokers is not the result of poor healing or ossointegration, but is due to the exposure of peri-implant tissues to tobacco smoke [83], possibly linking the smoking effects on implant survival to the smoking effects on periodontitis.

A smoking cessation protocol has been suggested to improve the success rate of Brånemark implants [85]. The protocol involved complete cessation of smoking for 1 week before and 8 weeks after initial implant placement. It was concluded that the protocol demonstrated considerable promise in improving the success rates of implant integration in smokers who complied; however, it was noted that the sample size for smokers was relatively small. Furthermore, as touched upon above and acknowledging the problems attached to this, the study did not include a randomization of patients in terms of those following the protocol and those continuing their smoking habit.

There seems to be no doubt that smoking can be associated with higher rates of implant failure and altered periimplant conditions, but as indicated above the magnitude of the problem is difficult to assess from available studies. In general, it seems desirable to improve clinical trials in the field of oral implants [86].

\section{Saliva and Caries}

Studies on the effects of smoking on saliva flow rates and composition show varying results and are difficult to compare [for a comprehensive review, see 7]. Tobacco usage immediately stimulates salivary flow, but there is no long term effect on saliva flow rates. The $\mathrm{pH}$ of saliva rises during smoking, but over longer time periods most studies indicate that smokers have slightly reduced $\mathrm{pH}$ and buffering power compared to nonsmokers. A consistent finding is an increased concentration of thiocyanate in saliva. A component in normal saliva, thiocyanate is also present in tobacco smoke, and its concentration in saliva can be used to monitor tobacco exposure. A recent study showed that smoking is associated with lower salivary cystatin activity and output of cystatin $\mathrm{C}$ during gingival inflammation [72]. Cystatins are thought to contribute to maintaining oral health by inhibiting certain proteolytic enzymes. In addition this study confirmed earlier results that showed no significant differences in salivary flow rates between smokers and non-smokers.

Rather few studies have shown a relationship between smoking and a higher incidence of dental caries [51, 87, 88]. Recent studies support these findings [89, 90]. There is no evidence of any direct aetiological relationship, but 
the findings of higher counts of lactobacillus and, although various results are reported, Streptococcus mutans in smokers [91] may explain this relationship. It is interesting, although not easy to explain, that maternal smoking is associated with the occurrence of caries in preschool children, even when adjusted for social class, nutritional status, and weekly expenditure on confectioneries [92].

In previous studies there was insufficient evidence to support an association between smokeless tobacco and dental caries [7]. A recent study from the USA, however, indicates an association, in particular in terms of root surface caries. This may be explained by the high proportion of sugar in some types of smokeless tobacco [93].

Thus, there are a few studies suggesting an association between tobacco usage and dental caries, although a direct aetiological relationship is lacking. It seems at least that smoking is a risk indicator of increased caries activity.

\section{Other Effects of Smoking on the Mouth}

\section{Aesthetics, Smell and Taste}

Smoking causes discoloration of teeth, dental restorations, and dentures, affecting the aesthetic appearance of the mouth [94, 95], and it contributes more to discoloration than does the consumption of coffee and tea [96]. Smoking is a common cause of halitosis, and it affects the acuity of smell and taste [97, 98]. Odor identification was affected in a dose-related manner and olfactory function improved upon cessation of smoking [97]. Nonsmokers were able to detect salt $(\mathrm{NaCl})$ concentrations 12-14 times lower than the lowest concentration heavy smokers were able to detect [99].

\section{Smoker's Palate}

Smoker's palate, especially seen in pipe smokers, is an asymptomatic lesion appearing as a white change in the palate often combined with multiple red dots located centrally in small elevated nodules (fig. 5). It is closely related to smoking habits $[100,101]$, and the prevalence is $1-2 \%$ in Scandinavia. Smoker's palate is not premalignant [102], whereas the palatal keratosis associated with reverse smoking, as seen primarily in Asia, is a premalignant lesion [103].

\section{Smoker's Melanosis and Hairy Tongue}

In non-Caucasians melanin pigmentation in the oral mucosa is normally seen; however, in North European Caucasians it is far less prevalent (about 10\%) and has normally a subtle appearance. A pigmentation prevalence of about $30 \%$, most prevalent on the anterior attached gingiva, is seen in heavy smokers (smokers melanosis) (fig. 6) [104]. Recently it was shown that smokers in a Turkish population had significantly more pigmented oral surfaces than non-smokers [105]. The changes are symptomless, it is not premalignant, and it seems that the pigmentation is reversible upon smoking cessation [104, 106]. Hairy tongue and coated tongue are other harmless lesions related to smoking, although they can be seen in nonsmokers as well $[100,101,107]$.

\section{Oral Candidosis}

A relationship between oral candidosis and smoking has been suggested for a long time (fig. 2), but the exact pathogenic influence of smoking is not known. The suspicion arises from studies in which patients with oral candidosis turned out to be smokers in all $[108,109]$ or in the vast majority of cases [110]. Another study of the oral presence of Candida strains in healthy adults and in patients with oral leukoplakia and erythematous candidosis also suggested that smoking is a predisposing factor for candidal infection [111]. After antimycotic therapy smokers had relapses of the candidal infection in all cases [109], and in HIV-infected patients smokers were less likely to respond to systemic antimycotic treatment than nonsmokers [112].

Further studies are indeed needed to establish a firm aetiological relationship between smoking and oral candidosis, but it seems fair to inform smokers about the possible relationship and consequences for treatment.

\section{Tobacco Intervention in Dental Practice}

Are dentists actively engaged in tobacco intervention matters? In several studies it has been shown that the majority of dentists consider encouraging their patients to stop smoking [113-118], but few dentists always or often discuss tobacco habits with their patients [113, 116-120]. It was recorded in a study from Italy that more dentists are engaged in tobacco cessation activities [121]. The main barriers to providing tobacco cessation services to patients are lack of reimbursement, lack of confidence in the effectiveness of advice from the dental profession, and lack of knowledge and material to hand out to patients [116-118, 120]. Although few studies are available, it seems that clinical interventions in dental care are as effective as those in other healthcare settings [122]. In spite of this, policies and practices of European dental schools need considerable improvement [123]. 


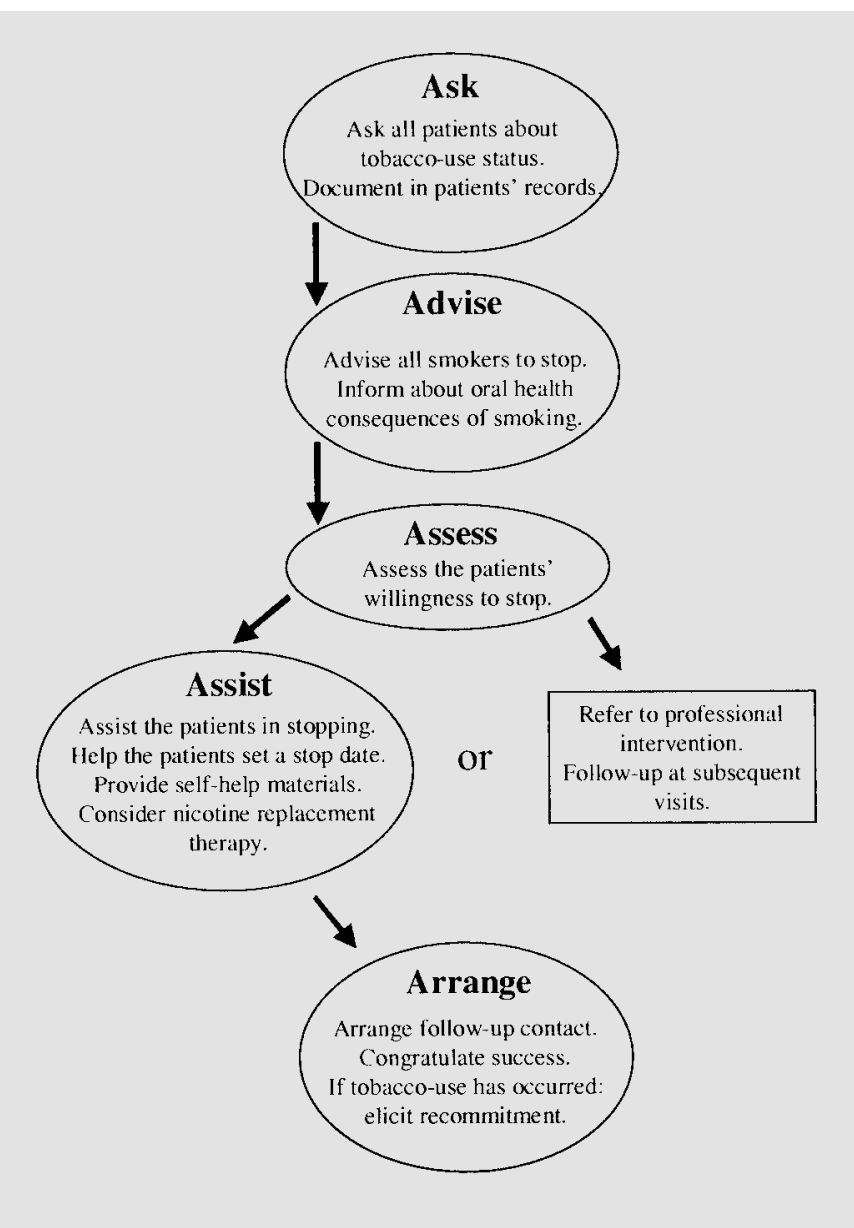

Fig. 7. The five As.

Tobacco intervention includes tobacco cessation activities, prevention, and public policy development. Preferably, dentists should be competent in all three areas. For the purpose of this review only tobacco counselling in daily practice will be touched upon. The World Dental Federation (FDI) adopted a Position Statement on Tobacco in 1996 [124] in which all oral health professionals are urged to integrate tobacco use prevention and cessation services into their routine and daily practice.

\section{Recommendations: How to Help Our Patients?}

Guidelines for healthcare providers about tobacco cessation activities are similar in Europe and the United States $[6,125]$. The 5 major steps (the 5 As) are designed to be brief, requiring 3 minutes or less of direct clinician time (fig. 7) [122, 126] [see also http://www.surgeongeneral.gov/tobacco/(go to 'Clinician materials'; consumer ma- terials are also available)]. The primary goal is to ensure that every patient who uses tobacco is identified and offered at least a brief intervention at each clinical visit. The following is a summary of the suggested guidelines [122], along with some personal opinions.

Ask patients about smoking. A system should be implemented that ensures that every patient at every visit is asked about tobacco use, and the answer documented in the patient's record.

Advise all smokers to stop. A prescriptive approach should be avoided. Rather, the healthcare professional or the dentist should provide the patients with information and advice, reinforcing the patients' own motivation when possible and emphasizing the benefits of stopping. Immediate benefits will often motivate the patients more effectively than long-term benefits. Grisly pictures and morbid statistics often stimulate patient denial. Instead, dentists should demonstrate the oral effects of tobacco if present, or inform patients about the increased risk of poor response or healing after dental procedures relevant to the patient.

Assess the patient's willingness to stop. If the patient is willing to make an attempt to quit, dentists should assist the patient. If a patient is not at all interested in stopping it is, in my view, rarely beneficial to push the patient. Instead, the dentist should accept the patient's decision and make a note in the record for future reference. Dentists should ensure that the patient is aware of the staff's willingness to help, for instance by providing the patient with written information or/and asking the patient in a subsequent visit to reconsider his or her decision. Depending on the training and resources of the dentist and staff, the following steps can be taken in the dental office, or the patient can be referred to a tobacco cessation specialist.

Assist the patient in stopping. If a patient has a desire to stop, the dentist should help the patient set a realistic quitting date which should be soon but not immediately so that the patient has time to prepare. If consultation time is limited, self-help materials that provide the patient with necessary information about smoking cessation can be provided. Nicotine replacement therapy (nicotine gum, inhaler, nasal spray, or skin patch) can be very helpful [122, 126-129]. Special consideration should be given to selected populations $[122,126]$. Whatever the approach, the dentist should see to it that the patient leaves the office with a concrete plan for stopping and information about how to prepare for the quitting date and how to successfully stop, keeping in mind that most smokers relapse three to five times before succeeding in stopping. 
Arrange follow-up contact. Follow-up contacts are very important as the chances of a successful outcome are improved when patients know their progress will be reviewed. The dentist should confirm the quitting date, show continuing support, and follow through if the patient was successful or encourage another try if unsuccessful. Follow-ups may be by telephone call, letter, office visit, or a combination of these, and if possible the dentist should arrange to see the patients within one or two weeks after the quitting date and consider a second follow-up one or two months later.

It is important that the entire dental team is aware of the relationship between smoking and oral problems. The clinical staff should be familiar with current facts and encouraged to actively participate in tobacco intervention routines. In particular, dental care workers should encourage tobacco preventive measures among adolescents [130, $131]$.

\section{Conclusions}

The lesions and conditions caused in whole or in part by tobacco use are well known, and there is weighty evidence that smoking has considerable influence on oral health. But tobacco use is a modifiable risk factor for oral and general disease, and an obvious professional interest in tobacco intervention can make a big difference in the health of an individual or the outcome of a given disease. Dentists have probably the greatest access to 'healthy' smokers in the healthcare system, and even in the absence of tobacco-related diseases in the mouth, the dentist will easily recognize the patient's smoking status. These facts place dentists in a favourable position to help prevent tobacco-related diseases, and interested practitioners should pursue more formal training in smoking cessation counselling, which should be as much a part of their job as plaque control and dietary advice.

\section{References}

1 Doll R, Hill AB: Smoking and carcinoma of the lung: Preliminary report. Br Med J 1950;77: 739-748.

2 Doll R, Peto R, Wheatley K, Gray R, Sutherland I: Mortality in relation to smoking: 40 years' observations on male British doctors. BMJ 1994;309:901-911.

3 Peto R, Darby S, Deo H, Silcocks P, Whitley E, Doll R: Smoking, smoking cessation, and lung cancer in the UK since 1950: Combination of national statistics with two case-control studies. BMJ 2000;321:323-329.

4 Funk GF, Karnell LH, Robinson RA, Zhen WK, Trask DK, Hoffman HT: Presentation, treatment, and outcome of oral cavity cancer: A National Cancer Data Base report. Head Neck 2002;24:165-180.

5 Christen AG, McDonald JL, Christen JA: The Impact of Tobacco Use and Cessation on Nonmalignant and Precancerous Oral and Dental Diseases and Conditions. Indianapolis, Indiana University School of Dentistry, 1991.

6 Mecklenburg RE, Greenspan D, Kleinman DV, Manley MW, Niessen LC, Robertson PB, Winn DE: Tobacco Effects in the Mouth: A National Cancer Institute and National Institute of Dental Research Guide for Health Professionals. Bethesda, US Department of Health and Human Services, Public Health Service, National Institutes of Health, 1994.

7 EU Working Group on Tobacco and Oral Health Consensus Meeting, Copenhagen, October 1997. Oral Dis 1998;4:48-67.

8 Parkin DM, Pisani P, Ferlay J: Estimates of the worldwide incidence of 25 major cancers in 1990. Int J Cancer 1999;80:827-841.
9 Parkin DM, Whelan SL, Ferlay J, Raymond L, Young J: Cancer Incidence in Five Continents. Lyon, International Agency for Research on Cancer, 1997, vol VII.

10 McCoy GD, Hecht SS, Wynder EL: The roles of tobacco, alcohol, and diet in the etiology of upper alimentary and respiratory tract cancers. Prev Med 1980;9:622-629.

11 International Agency for Research on Cancer: Tobacco Smoking. Lyon, IARC, 1986.

12 Blot WJ, McLaughlin JK, Winn DM, Austin DF, Greenberg RS, Preston-Martin S, Bernstein L, Schoenberg JB, Stemhagen A, Fraumeni JF Jr: Smoking and drinking in relation to oral and pharyngeal cancer. Cancer Res 1988; 48:3282-3287.

13 Franceschi S, Talamini R, Barra S, Baron AE, Negri E, Bidoli E, Serraino D, La Vecchia C: Smoking and drinking in relation to cancers of the oral cavity, pharynx, larynx, and esophagus in northern Italy. Cancer Res 1990;50:65026507.

14 Franceschi S, Levi F, La Vecchia C, Conti E, Dal Maso L, Barzan L, Talamini R: Comparison of the effect of smoking and alcohol drinking between oral and pharyngeal cancer. Int $\mathbf{J}$ Cancer 1999;83:1-4.

15 La Vecchia C, Boyle P, Franceschi S, Levi F, Maisonneuve P, Negri E, Lucchini F, Smans M: Smoking and cancer with emphasis on Europe. Eur J Cancer 1991;27:94-104.

16 Garrote LF, Herrero R, Reyes RM, Vaccarella S, Anta JL, Ferbeye L, Munoz N, Franceschi S: Risk factors for cancer of the oral cavity and oro-pharynx in Cuba. Br J Cancer 2001;85:4654.
17 Macfarlane GJ, Zheng T, Marshall JR, Boffetta P, Niu S, Brasure J, Merletti F, Boyle P. Alcohol, tobacco, diet and the risk of oral cancer: A pooled analysis of three case-control studies. Eur J Cancer [B] 1995;31B:181-187.

18 Scully C, Bedi R: Ethnicity and oral cancer. Lancet Oncol 2000;i:37-42.

19 Zain RB: Cultural and dietary factors of oral cancer and precancer: A brief overview. Oral Oncol 2001;37:205-210.

20 Axell TE: Oral mucosal changes related to smokeless tobacco usage: Research findings in Scandinavia. Eur J Cancer [B] 1993;29B:299302.

21 Lewin F, Norell SE, Johansson H, Gustavsson $\mathrm{P}$, Wennerberg J, Biorklund A, Rutqvist LE: Smoking tobacco, oral snuff, and alcohol in the etiology of squamous cell carcinoma of the head and neck: A population-based case-referent study in Sweden. Cancer 1998;82:13671375.

22 Winn DM: Surveillance of and Knowledge about Cancer Associated with Smokeless Tobacco Use; in: Smokeless Tobacco or Health: An International Perspective. Bethesda, US Department of Health and Human Services, Public Health Service, National Institutes of Health, National Cancer Institute, 1993, pp 11-18.

23 Nylander K, Dabelsteen E, Hall PA: The p53 molecule and its prognostic role in squamous cell carcinomas of the head and neck. J Oral Pathol Med 2000;29:413-425.

24 La Vecchia C, Franceschi S, Levi F, Lucchini F, Negri E: Diet and human oral carcinoma in Europe. Eur J Cancer [B] 1993;29B:17-22. 
25 La Vecchia C, Tavani A, Franceschi S, Levi F, Corrao G, Negri E: Epidemiology and prevention of oral cancer. Oral Oncol 1997;33: 302-312.

26 Lesch CA, Squier CA, Cruchley A, Williams DM, Speight P: The permeability of human oral mucosa and skin to water. J Dent Res 1989;68:1345-1349.

27 Zavras AI, Douglass CW, Joshipura K, Wu T, Laskaris G, Petridou E, Dokianakis G, Segas J, Lefantzis D, Nomikos P, Wang YF; Diehl SR Smoking and alcohol in the etiology of oral cancer: Gender-specific risk profiles in the south of Greece. Oral Oncol 2001;37:28-35.

28 Szabo G, Klenk G, Veer A, Nemeth Z: Correlation of the combination of alcoholism and smoking with the occurrence of cancer in the oral cavity: A screening study in an endangered population. Mund Kiefer Gesichtschir 1999;3: 119-122.

29 Kerawala CJ: Oral cancer, smoking and alcohol: The patients' perspective. Br J Oral Maxillofac Surg 1999;37:374-376.

30 Baric JM, Alman JE, Feldman RS, Chauncey $\mathrm{HH}$ : Influence of cigarette, pipe, and cigar smoking, removable partial dentures, and age on oral leukoplakia. Oral Surg Oral Med Ora Pathol 1982;54:424-429.

31 Banoczy J, Gintner Z, Dombi C: Tobacco use and oral leukoplakia. J Dent Educ 2001;65: 322-327.

32 Schepman KP, Bezemer PD, van der Meij EH, Smeele LE, van der Waal I: Tobacco usage in relation to the anatomical site of oral leukoplakia. Oral Dis 2001;7:25-27.

33 Greer RO Jr, Poulson TC: Oral tissue alterations associated with the use of smokeless tobacco by teenagers. I. Clinical findings. Oral Surg Oral Med Oral Pathol 1983;56:275-284.

34 Andersson G: Snuff-induced changes associated with the use of loose and portion-bag-packed Swedish moist snuff: A clinical, histological and follow-up study. Swed Dent J Suppl 1991; 75:1-89.

35 Idris AM, Warnakulasuriya KA, Ibrahim YE Nielsen R, Cooper D, Johnson NW: Toombakassociated oral mucosal lesions in Sudanese show a low prevalence of epithelial dysplasia. J Oral Pathol Med 1996;25:239-244.

36 Zhang X, Schmitz W, Gelderblom HR, Reichart PA: Shammah-induced oral leukoplakialike lesions. Oral Oncol 2001;37:609-612.

37 Larsson A, Axell T, Andersson G: Reversibility of snuff dippers' lesion in Swedish moist snuff users: A clinical and histologic follow-up study. J Oral Pathol Med 1991;20:258-264.

38 Silverman S Jr, Gorsky M, Lozada F: Oral leukoplakia and malignant transformation: A follow-up study of 257 patients. Cancer 1984;53. 563-568.

39 Schepman KP, van der Meij EH, Smeele LE, van der Waal I: Malignant transformation of oral leukoplakia: A follow-up study of a hospital-based population of 166 patients with ora leukoplakia from The Netherlands. Oral Oncol 1998:34:270-275.
40 Gupta PC, Murti PR, Bhonsle RB, Mehta FS, Pindborg JJ: Effect of cessation of tobacco use on the incidence of oral mucosal lesions in a 10 -yr follow-up study of 12,212 users. Oral Dis 1995;1:54-58.

41 Jaber MA, Porter SR, Gilthorpe MS, Bedi R, Scully C: Risk factors for oral epithelial dysplasia: The role of smoking and alcohol. Oral Oncol 1999;35:151-156.

42 Roed-Petersen B: Effect on oral leukoplakia of reducing or ceasing tobacco smoking. Acta Derm Vener 1982;62:164-167.

43 Pindborg JJ, Reibel J, Roed-Peterson B, Mehta FS: Tobacco-induced changes in oral leukoplakic epithelium. Cancer 1980;45:23302336.

44 Kinane DF, Chestnutt IG: Smoking and periodontal disease. Crit Rev Oral Biol Med 2000; 11:356-365.

45 Johnson GK, Slach NA: Impact of tobacco use on periodontal status. J Dent Educ 2001;65: 313-321.

46 Bolin A: Proximal alveolar bone loss in a longitudinal radiographic investigation. Swed Dent J Suppl 1986;35:1-108.

47 Bergstrom J, Preber H: Tobacco use as a risk factor. J Periodontol 1994;65(suppl):545-550.

48 Grossi SG, Zambon JJ, Ho AW, Koch G, Dunford RG, Machtei EE, Norderyd OM, Genco RJ: Assessment of risk for periodontal disease. I. Risk indicators for attachment loss. J Periodontol 1994;65:260-267.

49 Grossi SG, Genco RJ, Machtei EE, Ho AW, Koch G, Dunford R, Zambon JJ, Hausmann E: Assessment of risk for periodontal disease. II. Risk indicators for alveolar bone loss. J Periodontol 1995;66:23-29.

50 Machtei EE, Dunford R, Hausmann E, Grossi SG, Powell J, Cummins D, Zambon JJ, Genco $\mathrm{RJ}$ : Longitudinal study of prognostic factors in established periodontitis patients. J Clin Periodontol 1997;24:102-109.

51 Axelsson P, Paulander J, Lindhe J: Relationship between smoking and dental status in 35-, 50-, 65-, and 75-year-old individuals. J Clin Periodontol 1998;25:297-305.

52 Norderyd O, Hugoson A, Grusovin G: Risk of severe periodontal disease in a Swedish adult population. A longitudinal study. J Clin Periodontol 1999;26:608-615.

53 Bergstrom J, Preber H: The influence of cigarette smoking on the development of experimental gingivitis. J Periodontal Res 1986;21: 668-676.

54 Danielsen B, Manji F, Nagelkerke N, Fejerskov $\mathrm{O}$, Baelum V: Effect of cigarette smoking on the transition dynamics in experimental gingivitis. J Clin Periodontol 1990;17:159-164.

55 Albandar JM, Streckfus CF, Adesanya MR, Winn DM: Cigar, pipe, and cigarette smoking as risk factors for periodontal disease and tooth loss. J Periodontol 2000;71:1874-1881.

56 Bergstrom J, Eliasson S, Dock J: A 10-year prospective study of tobacco smoking and periodontal health. J Periodontol 2000;71:13381347.

57 Haffajee AD, Socransky SS: Relationship of cigarette smoking to attachment level profiles. J Clin Periodontol 2001;28:283-295.
58 Scabbia A, Cho KS, Sigurdsson TJ, Kim CK, Trombelli L: Cigarette smoking negatively affects healing response following flap debridement surgery. J Periodontol 2001;72:43-49.

59 Tomar SL, Asma S: Smoking-attributable periodontitis in the United States: Findings from NHANES III. National Health and Nutrition Examination Survey. J Periodontol 2000;71 743-751.

60 van der Weijden GA, de Slegte C, Timmerman MF, van der Velden U: Periodontitis in smokers and non-smokers: Intra-oral distribution of pockets. J Clin Periodontol 2001;28:955-960.

61 Chen X, Wolff L, Aeppli D, Guo Z, Luan W, Baelum V, Fejeskov O: Cigarette smoking, salivary/gingival crevicular fluid cotinine and periodontal status: A 10-year longitudinal study. J Clin Periodontol 2001;28:331-339.

62 Norderyd O, Hugoson A: Risk of severe periodontal disease in a Swedish adult population: A cross-sectional study. J Clin Periodontol 1998;25:1022-1028.

63 Haber J, Wattles J, Crowley M, Mandell R, Joshipura K, Kent RL: Evidence for cigarette smoking as a major risk factor for periodontitis. J Periodontol 1993;64:16-23.

64 Machtei EE, Hausmann E, Dunford R, Grossi S, Ho A, Davis G, Chandler J, Zambon J, Genco RJ: Longitudinal study of predictive factors for periodontal disease and tooth loss. J Clin Periodontol 1999;26:374-380.

65 Machuca G, Rosales I, Lacalle JR, Machuca C, Bullon P: Effect of cigarette smoking on periodontal status of healthy young adults. J Periodontol 2000;71:73-78.

66 Bostrom L, Bergstrom J, Dahlen G, Linder LE Smoking and subgingival microflora in periodontal disease. J Clin Periodontol 2001;28: 212-219.

67 Darby IB, Hodge PJ, Riggio MP, Kinane DF: Microbial comparison of smoker and nonsmoker adult and early-onset periodontitis patients by polymerase chain reaction. J Clin Periodontol 2000;27:417-424.

68 Haffajee AD, Socransky SS: Relationship of cigarette smoking to the subgingival microbiota. J Clin Periodontol 2001;28:377-388.

69 Faddy MJ, Cullinan MP, Palmer JE, Westerman B, Seymour GJ: Ante-dependence modeling in a longitudinal study of periodontal disease: The effect of age, gender, and smoking status. J Periodontol 2000;71:454-459.

70 Barbour SE, Nakashima K, Zhang JB, Tangada S, Hahn CL, Schenkein HA, Tew JG: Tobacco and smoking: Environmental factors that modify the host response (immune system) and have an impact on periodontal health. Crit Rev Oral Biol Med 1997;8:437-460.

71 Bostrom L, Linder LE, Bergstrom J: Smoking and GCF levels of IL-1beta and IL-1 ra in periodontal disease. J Clin Periodontol 2000;27: 250-255.

72 Lie MA, Loos BG, Henskens YM, Timmerman MF, Veerman EC, van der Velden U, van der Weijden GA: Salivary cystatin activity and cystatin $\mathrm{C}$ in natural and experimental gingivitis in smokers and non-smokers. J Clin Periodontol 2001;28:979-984. 
73 Mooney J, Hodge PJ, Kinane DF: Humoral immune response in early-onset periodontitis: Influence of smoking. J Periodontal Res 2001; 36:227-232.

74 Persson L, Bergstrom J, Ito H, Gustafsson A: Tobacco smoking and neutrophil activity in patients with periodontal disease. J Periodontol 2001;72:90-95.

75 Rezavandi K, Palmer RM, Odell EW, Scott DA, Wilson RF: Expression of ICAM-1 and Eselectin in gingival tissues of smokers and nonsmokers with periodontitis. J Oral Pathol Med 2002;31:59-64.

76 Bergstrom J, Bostrom L: Tobacco smoking and periodontal hemorrhagic responsiveness. J Clin Periodontol 2001;28:680-685.

77 Palmer RM, Matthews JP, Wilson RF: Nonsurgical periodontal treatment with and without adjunctive metronidazole in smokers and non-smokers. J Clin Periodontol 1999;26:158163.

78 Robertson PB, Walsh M, Greene J, Ernster V, Grady D, Hauck W: Periodontal effects associated with the use of smokeless tobacco. J Periodontol 1990;61:438-443.

79 Gelskey SC: Cigarette smoking and periodontitis: Methodology to assess the strength of evidence in support of a causal association. Community Dent Oral Epidemiol 1999;27:16-24.

80 Esposito M, Hirsch JM, Lekholm U, Thomsen P: Biological factors contributing to failures of osseointegrated oral implants. II. Etiopathogenesis. Eur J Oral Sci 1998;106:721-764.

81 Berge TI, Gronningsaeter AG: Survival of single crystal sapphire implants supporting mandibular overdentures. Clin Oral Implants Res 2000;11:154-162.

82 Carlsson GE, Lindquist LW, Jemt T: Longterm marginal periimplant bone loss in edentulous patients. Int J Prosthodont 2000;13:295302.

83 Lambert PM, Morris HF, Ochi S: The influence of smoking on 3-year clinical success of osseointegrated dental implants. Ann Periodontol 2000;5:79-89.

84 Quirynen M, Peeters W, Naert I, Coucke W, van Steenberghe D: Peri-implant health around screw-shaped c.p. titanium machined implants in partially edentulous patients with or without ongoing periodontitis. Clin Oral Implants Res 2001;12:589-594.

85 Bain CA: Smoking and implant failure: Benefits of a smoking cessation protocol. Int J Oral Maxillofac Implants 1996;11:756-759.

86 Esposito M, Couthard P, Worthington HV, Jokstad A: Quality assessment of randomized controlled trials of oral implants. Int $\mathrm{J}$ Oral Maxillofac Implants 2001;16:783-792.

87 Hirsch JM, Livian G, Edward S, Noren JG: Tobacco habits among teenagers in the city of Goteborg, Sweden, and possible association with dental caries. Swed Dent J 1991;15:117123.

88 Jette AM, Feldman HA, Tennstedt SL: Tobacco use: A modifiable risk factor for dental disease among the elderly. Am J Public Health 1993; $83: 1271-1276$
89 Sakki T: Lifestyle and oral health of 55-yearsolds; thesis, Oulu, 1999

90 Sgan-Cohen HD, Katz J, Horev T, Dinte A, Eldad A: Trends in caries and associated variables among young Israeli adults over 5 decades. Community Dent Oral Epidemiol 2000;28:234-240.

91 Sakki T, Knuuttila M: Controlled study of the association of smoking with lactobacilli, mutans streptococci and yeasts in saliva. Eur $\mathbf{J}$ Oral Sci 1996; 104:619-622.

92 Williams SA, Kwan SY, Parsons S: Parental smoking practices and caries experience in preschool children. Caries Res 2000;34:117122.

93 Tomar SL, Winn DM: Chewing tobacco use and dental caries among US men. J Am Dent Assoc 1999; 130:1601-1610.

94 Eriksen HM, Nordbo H: Extrinsic discoloration of teeth. J Clin Periodontol 1978;5:229236.

95 Asmussen E, Hansen EK: Surface discoloration of restorative resins in relation to surface softening and oral hygiene. Scand J Dent Res 1986;94:174-177.

96 Ness L, Rosekrans DL, Welford JF: An epidemiologic study of factors affecting extrinsic staining of teeth in an English population. Community Dent Oral Epidemiol 1977;5: 55-60.

97 Frye RE, Schwartz BS, Doty RL: Dose-related effects of cigarette smoking on olfactory function. JAMA 1990;263:1233-1236.

98 Pasquali B: Menstrual phase, history of smoking, and taste discrimination in young women. Percept Mot Skills 1997;84:1243-1246.

99 Jackson JA: Heavy smoking and sodium chloride hypogeusia. J Dent Res 1967;46:742744.

100 Salonen L, Axell T, Hellden L: Occurrence of oral mucosal lesions, the influence of tobacco habits and an estimate of treatment time in an adult Swedish population. J Oral Pathol Med 1990;19:170-176.

101 Andersson G, Vala EK, Curvall M: The influence of cigarette consumption and smoking machine yields of tar and nicotine on the nicotine uptake and oral mucosal lesions in smokers. J Oral Pathol Med 1997;26:117123.

102 Axell T: Occurrence of leukoplakia and some other oral white lesions among 20,333 adult Swedish people. Community Dent Oral Epidemiol 1987;15:46-51.

103 Mehta FS, Jalnawalla PN, Daftary DK, Gupta PC, Pindborg JJ: Reverse smoking in Andhra Pradesh, India: Variability of clinical and histologic appearances of palatal changes. Int J Oral Surg 1977;6:75-83.

104 Axell T, Hedin CA: Epidemiologic study of excessive oral melanin pigmentation with special reference to the influence of tobacco habits. Scand J Dent Res 1982;90:434-442.

105 Unsal E, Paksoy C, Soykan E, Elhan AH, Sahin M: Oral melanin pigmentation related to smoking in a Turkish population. Community Dent Oral Epidemiol 2001;29:272-277.
106 Hedin CA, Pindborg JJ, Axell T: Disappearance of smoker's melanosis after reducing smoking. J Oral Pathol Med 1993;22:228230

107 Campisi G, Margiotta V: Oral mucosal lesions and risk habits among men in an Italian study population. J Oral Pathol Med 2001;30: 22-28.

108 Arendorf TM, Walker DM, Kingdom RJ, Roll JR, Newcombe RG: Tobacco smoking and denture wearing in oral candidal leukoplakia. Br Dent J 1983;155:340-343.

109 Holmstrup P, Bessermann M: Clinical, therapeutic, and pathogenic aspects of chronic oral multifocal candidiasis. Oral Surg Oral Med Oral Pathol 1983;56:388-395.

110 Arendorf TM, Walker DM: Tobacco smoking and denture wearing as local aetiological factors in median rhomboid glossitis. Int J Oral Surg 1984;13:411-415.

111 Rindum JL, Stenderup A, Holmstrup P: Identification of Candida albicans types related to healthy and pathological oral mucosa. J Oral Pathol Med 1994;23:406-412.

112 Silverman S Jr, Gallo JW, McKnight ML, Mayer P, deSanz S, Tan MM: Clinical characteristics and management responses in 85 HIV-infected patients with oral candidiasis. Oral Surg Oral Med Oral Pathol Oral Radiol Endod 1996;82:402-407.

113 Telivuo M, Kallio P, Berg MA, Korhonen HJ, Murtomaa H: Smoking and oral health: A population survey in Finland. J Public Health Dent 1995;55:133-138.

114 Chestnutt IG, Binnie VI: Smoking cessation counselling: A role for the dental profession? Br Dent J 1995;179:411-415.

115 Cowan CG, Gregg TA, Kee F: Prevention and detection of oral cancer: The views of primary care dentists in Northern Ireland. Br Dent $\mathrm{J}$ 1995; 179:338-342.

116 John JH, Yudkin P, Murphy M, Ziebland S, Fowler GH: Smoking cessation interventions for dental patients: Attitudes and reported practices of dentists in the Oxford region. $\mathrm{Br}$ Dent J 1997;183:359-364.

117 Warnakulasuriya KA, Johnson NW: Dentists and oral cancer prevention in the UK: Opinions, attitudes and practices to screening for mucosal lesions and to counselling patients on tobacco and alcohol use: Baseline data from 1991. Oral Dis 1999;5:10-14.

118 Allard RH: Tobacco and oral health: Attitudes and opinions of European dentists. A report of the EU working group on tobacco and oral health. Int Dent J 2000;50:99-102.

119 Tomar SL, Husten CG, Manley MW: Do dentists and physicians advise tobacco users to quit? J Am Dent Assoc 1996;127:259-265.

120 Dolan TA, McGorray SP, Grinstead-Skigen CL, Mecklenburg R: Tobacco control activities in U.S. dental practices. J Am Dent Assoc 1997; 128:1669-1679.

121 Lodi G, Bez C, Rimondini L, Zuppiroli A, Sardella A, Carrassi A: Attitude towards smoking and oral cancer prevention among northern Italian dentists. Oral Oncol 1997; 33:100-104. 
122 Fiore MC, Bailey WC, Cohen SJ: Treating Tobacco Use and Dependence. Rockville, US Department of Health \& Human Services, Public Health Service, 2000.

123 McCartan BE, Shanley DB: Policies and practices of European dental schools in relation to smoking: The place of tobacco education in the undergraduate dental curriculum. $\mathrm{Br}$ Dent J 1995; 179:306-308.

124 Akerberg O: Editorial. FDI World 1996;5:56.

125 Watt R, Robinson M: Helping Smokers to Stop: A Guide for the Dental Team. London, Health Education Authority, 1999.
126 Fiore MC, Bailey WC, Cohen SJ: A clinical practice guideline for treating tobacco use and dependence: A US Public Health Service Report. JAMA 2000;283:3244-3254.

127 Bolliger CT, Zellweger JP, Danielsson T, van Biljon X, Robidou A, Westin A, Perruchoud AP, Sawe U: Smoking reduction with oral nicotine inhalers: Double blind, randomised clinical trial of efficacy and safety. BMJ 2000; 321:329-333.

128 Silagy C, Lancaster T, Stead L, Mant D, Fowler G: Nicotine replacement therapy for smoking cessation. Cochrane Database Syst Rev 2001:CD000146.
129 West R, Shiffman S: Effect of oral nicotine dosing forms on cigarette withdrawal symptoms and craving: A systematic review. Psychopharmacology (Berl) 2001;155:115-122.

130 Skjoldebrand J, Gahnberg L: Tobacco preventive measures by dental care staff: An attempt to reduce the use of tobacco among adolescents. Swed Dent J 1997;21:49-54.

131 Kentala J, Utriainen P, Pahkala K, Mattila K: Can brief intervention through community dental care have an effect on adolescent smoking? Prev Med 1999;29:107-111. 